\title{
“COMO É QUE FAZ PRA SAIR DA ILHA?" PONTES E ATRAVESSAMENTOS ENTRE A PANDEMIA, O SUAS E A MUSICOTERAPIA
}

\author{
"HOW DO WE LEAVE OF THE ISLAND?" BRIDGES AND CROSSINGS \\ AMONG PANDEMIA, SUAS AND MUSIC THERAPY
}

Kezia Paz ${ }^{1}$

Resumo: O objetivo deste artigo é propor uma reflexão acerca dos impactos da Pandemia de COVID-19 no trabalho dos musicoterapeutas que atuam no Sistema Único de Assistência Social (SUAS), refletindo também sobre a acessibilidade da musicoterapia para populações mais vulnerabilizadas. A proposta é fazer uma breve discussão sobre o tema, e relatar a experiência da autora como musicoterapeuta trabalhadora do SUAS, e os impactos sofridos no atendimento musicoterapêutico a grupos de mulheres em situação de violência e vulnerabilidade social, usuárias de um serviço da rede socioassistencial em São Paulo.

Palavras-chave: Pandemia,COVID19, SUAS, musicoterapia

Abstract: The objective of this article is to provide a reflection about the impacts of the COVID-19 Pandemic in the music therapists work in the Unified Social Assistance System (SUAS), also reflecting on the accessibility of music therapy for the most vulnerable population. The objective is to have a brief discussion on the topic, and to relate the experience of the author as a music therapist who is working with SUAS, and the suffered impacts in music therapy attendance to groups of women in situations of violence and social vulnerability who are users of a social and assistance network in São Paulo.

Keywords: Pandemic,COVID19, SUAS, music therapy

\footnotetext{
${ }^{1}$ Musicoterapeuta, Pós-graduada em Controle Social das Políticas Públicas pela Escola Superior de Gestão e Contas Públicas do TCM-SP, Pós-graduanda em Prevenção e Enfrentamento da Violência para Garantia dos Direitos Humanos pela Faculdade de Ciências Médicas da Santa Casa de São Paulo. E-mail: musicoterapeutakeziapaz@gmail.com
} 


\section{RBMT}

Revista Brasileira

de Musicoterapia

\section{Introdução}

Este lugar é uma maravilha /Mas como é que faz pra sair da ilha? (A ponte - Lenine)

Este trabalho pretende abordar a atual conjuntura envolvendo os impactos da Pandemia na Política de Assistência Social, e situar a musicoterapia nesse contexto. O trabalho reflexivo, de enfoque qualitativo tem caráter exploratório e descritivo, com base em levantamento bibliográfico e de dados sobre o tema, a fim de contribuir com a discussão teórico-conceitual e prática sobre o campo da musicoterapia social e comunitária.

Neste trabalho, corroboramos com Arndt e Maheirie (2019), quando dizem que mesmo em publicações que se referem a formas outras de se fazer Musicoterapia que não a clínica tradicional, a base epistemológica é construída também a partir de teorias variadas.

Nesse sentido utilizaremos os aportes epistêmicos da musicoterapia social e comunitária conforme Pellizzari (2010 e 2011), Cunha (2016) e Arndt e Maheirie (2019 e 2020), destacando a perspectiva psicossocial que compreende os entrelaçamentos entre os contextos político-sociais e os processos de saúde-doença. Os conceitos de determinantes sociais em saúde e epidemiologia crítica são importantes norteadores nesse artigo, pois tratam de um olhar aprofundado sobre como os agravos em saúde são atravessados pelas desigualdades sociais.

No que se refere à pesquisas que relacionam a musicoterapia com as políticas públicas, temos como balizadoras deste trabalho as contribuições de Santos (2011); Dreher (2011); Oselame (2013); Andrade e Cunha (2015); Chagas, Brasil, e Cabral (2018); com destaque para Santana (2016), que se debruça especificamente sobre o Sistema Único de Assistência Social (SUAS), foco desse texto.

Neste artigo pretende-se expor um breve relato da experiência da 
autora como musicoterapeuta em uma prática no contexto do SUAS, que se inspira em atuações com uma perspectiva social e comunitária, tais como as relatadas nos trabalhos de Krob e Silva (2012), Krob (2013); Steffen (2012 e 2014) e Santos (2019) com práticas voltadas à mulheres e pautas de desigualdades de gênero; Valentin (2018) no trabalho com pessoas em situação de vulnerabilidade social; e Arndt (2015) em uma atuação em um Centro de Referência da Assistência Social (CRAS), um dos principais serviços do SUAS.

Considerando a via política da música (Ikeda, 2001) e a via política da clínica (Gondar, 2004), compreendemos a importância de pautar a musicoterapia sob um olhar político conforme nos aponta Reis e Freire (2020). A partir disso, é possível tecer olhares críticos sobre nossos fazeres, tal como esse trabalho se propõe.

\section{Uma breve análise de conjuntura sobre o SUAS e a pandemia}

A Política de Assistência Social que temos atualmente foi instituída na Constituição Federal de 1988, compondo juntamente com a Saúde e Previdência o chamado tripé da Seguridade Social. Temos como referência inicial do processo de efetivação desse direito a Lei Orgânica da Assistência Social (LOAS) de 1993. Já a Política Nacional de Assistência Social (PNAS) foi instituída em 2004, apresentando diretrizes para efetivação da assistência social como direito e apresentando os eixos para a consolidação do Sistema Único de Assistência Social (SUAS), que foi criado no ano seguinte, em 2005, e que foi aprovado como Lei no ano de 2011.

$\mathrm{Na}$ Conferência Nacional Democrática da Assistência Social (CNDAS) de 2019, o debate coletivo trouxe destaque para os retrocessos vivenciados na política de assistência social, apontando as ameaças e as demandas por direitos que só aumentam diante do aprofundamento da desigualdade,

Revista Brasileira de Musicoterapia - Ano XXIIn 28 ANO 2020

PAZ, Kezia. "Como é que faz pra sair da ilha?" Pontes e atravessamentos entre a pandemia, o SUAS e a musicoterapia

(p. $53-70)$ 
ampliação da pobreza, das violências e das desproteções (CNDAS, 2019).

A Pandemia de COVID $-19^{2}$ chegou ao Brasil acentuando uma crise de saúde pública e econômica que já vinha sendo gerada há algum tempo. Temos observado inúmeros retrocessos nas políticas sociais, e um processo contínuo de desfinanciamento público, por exemplo a Emenda Constitucional $n^{\circ} 95^{3}$, que impõe o teto de gastos públicos e impede investimentos na seguridade social por vinte exercícios financeiros (vinte anos). Relatórios organizados por pesquisadores da Fundação Getúlio Vargas (FGV) e do Núcleo de Estudos da Burocracia (NEB), publicados entre junho e agosto de 2020, trouxeram a público dados importantes para refletirmos o impacto da Pandemia no trabalho dentro do Sistema Único de Assistência Social (SUAS), bem como para mostrar a importância desses serviços para o enfrentamento aos desafios impostos pelas crise econômica e de saúde pública. Segundo a pesquisa, menos da metade dos servidores receberam Equipamento de Proteção Individual (EPI) para atuar nos serviços, e 74\% dos trabalhadores afirmaram que a pandemia causou impactos negativos em sua saúde mental (LOTTA et al, 2020).

Durante esse período notamos que o foco do debate público em relação ao enfrentamento à crise esteve muito relacionado às áreas de saúde e economia. Porém, cabe ressaltar que a assistência social teve um grande destaque quando o assunto do auxílio emergencial foi colocado em pauta. Mas para além da questão de transferência de renda, o SUAS se mostrou fundamental para minimizar os danos da pandemia, principalmente entre os mais pobres. Trata-se de uma política especializada no sofrimento humano e nas vulnerabilidades que decorrem da desigualdade, com ações que impactam nos projetos de vida, na alteração dos padrões dos vínculos sociais, nos

\footnotetext{
${ }^{2}$ COVID-19 é a doença infecciosa causada pelo novo coronavírus, identificado pela primeira vez em dezembro de 2019, em Wuhan, na China.

${ }^{3}$ Emenda Constitucional no 95 disponível no link:

http://www.planalto.gov.br/ccivil 03/constituicao/emendas/emc/emc95.htm
}

Revista Brasileira de Musicoterapia - Ano XXIIn 28 ANO 2020

PAZ, Kezia."Como é que faz pra sair da ilha?" Pontes e atravessamentos entre a pandemia, o SUAS e a musicoterapia

(p. $53-70)$ 
carecimentos sociais e econômicos (CNDAS, 2019). Com isso é possível perceber aproximações nos atendimentos da área da saúde pública com atendimentos ofertados no SUAS, onde as tecnologias desenvolvidas para a saúde podem ser utilizadas na assistência social (De Oliveira, e Kahhale, 2020).

Deste modo, podemos compreender que o SUAS também deve ser encarado como política pública essencial para construção de enfrentamentos a pandemias, e crises de diferentes segmentos.

\section{A Musicoterapia e o SUAS}

A Musicoterapia passou a integrar o SUAS, e a Política Nacional de Assistência Social (PNAS) em 2011, através da Resolução № $17^{4}$ do Conselho Nacional de Assistência Social (CNAS). Com isso, se tornou cada vez mais necessária a participação política da categoria profissional em debates sobre a política de assistência e suas intersecções com outras pastas, e no contexto da pandemia de Covid-19 não poderia ser diferente.

Em São Paulo, com objetivo de apoiar trabalhadores do SUAS no contexto da pandemia da Covid-19, o Fórum Estadual de trabalhadores do Sistema Único de Assistência Social do Estado de São Paulo (FETSUAS-SP), construiu coletivamente um canal de denúncias ${ }^{5}$, para informar aos trabalhadores sobre os órgãos e instituições responsáveis por fiscalizar profissões, políticas públicas, e o cumprimento da lei trabalhista. O contexto da pandemia evidenciou algumas dificuldades já enfrentadas pelos trabalhadores dessa política, tornando ainda mais frágeis e complexas as relações de trabalho, e a garantia de direitos. A Associação de Profissionais e Estudantes

\footnotetext{
${ }^{4}$ Resolução disponível no link: http://www.mds.gov.br/webarquivos/legislacao/assistencia social/resolucoes/2011/

${ }^{5}$ Documento disponível no link: https://drive.google.com/documentocanaldedenunciasfetsuassp
}

Revista Brasileira de Musicoterapia - Ano XXIIn² 28 ANO 2020

PAZ, Kezia."Como é que faz pra sair da ilha?" Pontes e atravessamentos entre a pandemia, o SUAS e a musicoterapia

(p. $53-70)$ 
de Musicoterapia do Estado de São Paulo (APEMESP), que integra a coordenação deste Fórum, compôs esse documento de importante visibilidade a nível estadual, e de grande relevância para o debate da conjuntura sobre a política de assistência social em meio a pandemia. Essa ação pode ser encarada sob a perspectiva da importância de enxergarmos as especificidades de trabalhadores dessa política, incluindo os Musicoterapeutas.

Em uma consulta ao Ministério da Cidadania, via portal do Serviço de Informação ao Cidadão, em julho de 2020, sobre o quantitativo de musicoterapeutas registrados como profissionais atuantes no SUAS, a Secretaria Nacional da Assistência Social (SNAS), informou a quantidade atual de 148 (cento e quarenta e oito) trabalhadores registrados no sistema, distribuídos em 19 estados brasileiros. Entre os principais serviços onde estão alocados estes profissionais são os Centros de Convivência, com registro de 62 (sessenta e dois) musicoterapeutas, Centros-dia com 54 (cinquenta e quatro), e Centros de Referência da Assistência Social (CRAS), com 15 (quinze) musicoterapeutas. Entre os estados que concentram maior quantidade de registros estão São Paulo com 47 (quarenta e sete) profissionais registrados no sistema, Paraná com 20 (vinte), Minas Gerais com 15 (quinze) e Rio Grande do Sul também com 15 (quinze) musicoterapeutas.

Esses dados devem ser problematizados quanto à confiabilidade, em decorrência das múltiplas variáveis envolvidas no processo de gestão dos serviços e contratação de trabalhadores do SUAS. Muitas contratações são feitas por Organizações da Sociedade Civil em parcerias firmadas com o poder público ${ }^{6}$. Deste modo, profissionais são contratados de forma terceirizada, o que além de ser uma forma precarizada de relação de trabalho, dificulta o registro exato da função exercida nos equipamentos. Muitos musicoterapeutas

\footnotetext{
${ }^{6}$ O Marco Regulatório das Organizações da Sociedade Civil - MROSC foi regulamentado pela Lei ำ 13.019, de 31 de julho de 2014 trata do estabelecimento do regime jurídico das parcerias entre a administração pública e as organizações da sociedade civil.
}

\section{Revista Brasileira de Musicoterapia - Ano XXIIn 28 ANO 2020}


que atuam nesse campo acabam sendo registrados pelas gestões de serviços como oficineiros. Ou ainda, temos a problemática que envolve a não regulamentação da profissão, que dá espaço para que profissionais de outras áreas exerçam atividades que não correspondem à musicoterapia, mas que são vistas e registradas como tal pela gestão dos serviços.

Trata-se, portanto de dados significativos para a classe de musicoterapeutas, no sentido de nos provocar a problematizar a estruturação e precarização dessa política pública. Pois se ela não está sendo executada de forma efetiva, o espaço do musicoterapeuta dentro do corpo de recursos humanos dos serviços, conforme a resolução № 17/2011 do Conselho Nacional de Assistência Social prevê, não pode ser garantido.

Cabe, portanto questionar, quais são as condições de trabalho dos musicoterapeutas atuantes nesse campo? Quais escolhas esses profissionais podem ou não fazer para garantir um trabalho de qualidade, do ponto de vista prático, técnico e ético-político? Qual a importância da atuação de profissionais nessa área para ampliar a presença da musicoterapia no país, levando-a para espaços com muita demanda, e poucos recursos humanos e orçamentários? E que populações têm menos acesso a essa prática, principalmente quando ela é impactada por crises e pela má gestão de políticas públicas?

Esses e outros questionamentos podem ser explorados nesse campo uma vez que de acordo com Arndt e Maheirie (2019, p.63) "construções epistemológicas em torno da Musicoterapia Social e Comunitária ainda são incipientes na musicoterapia". Esse trabalho busca com essas questões, suscitar o debate na classe, ampliando perspectivas de atuação e de pesquisa, para que possamos avançar e garantir nosso espaço no SUAS e em outras políticas públicas com os devidos direitos e a valorização necessária, que toda e qualquer prática profissional requer.

Revista Brasileira de Musicoterapia - Ano XXIIn 28 ANO 2020 


\section{Atendimento musicoterapêutico para grupo de mulheres em situação de violência e vulnerabilidade social no CDCM}

O CDCM é um serviço da Proteção Especial de média complexidade conveniado com a Secretaria Municipal de Assistência e Desenvolvimento Social (SMADS) da Prefeitura do Município de São Paulo. O CDCM Helena Vitória se encontra na região de Guaianases, extremo da periferia da cidade de São Paulo, onde existe uma escassez socioassistencial e de oportunidades de acessos à muitas políticas públicas de maneira significativa. Nesse território há uma concentração da população negra que, em decorrência do racismo estrutural, é excluída de acessos a serviços e direitos, como saúde, educação e cultura.

Segundo dados do Mapa da Desigualdade da cidade de São Paulo ${ }^{7}$, do ano de 2020 elaborado pela Rede Nossa São Paulo ${ }^{8}$, no território de Guaianases, a proporção da população feminina em relação ao total da população da cidade é de 51,6\%. A proporção de ocorrências de violência contra a mulher, incluindo todas as categorias, para cada dez mil mulheres na faixa etária de 20 a 59 anos, nesse território é de 299,3.

Nesse contexto, o CDCM vem oferecer proteção e apoio a todas as mulheres do território, principalmente às mulheres em situação de vulnerabilidade, especialmente, violência doméstica e familiar, causadora de lesão, sofrimento físico, sexual, psicológico, patrimonial ou dano moral. O maior objetivo do trabalho desenvolvido no equipamento é acolher as mulheres em

\footnotetext{
${ }^{7}$ Estudo sobre indicadores dos 96 distritos da cidade de São Paulo, que revela a distância socioeconômica entre as melhores e piores regiões.

${ }^{8}$ A Rede Nossa São Paulo (RNSP) é uma organização da sociedade civil que tem por missão mobilizar diversos segmentos da sociedade para, em parceria com instituições públicas e privadas, construir e se comprometer com uma agenda e um conjunto de metas, articular e promover ações, visando a uma cidade de São Paulo justa, democrática e sustentável.
} 
situação de violência, oferecendo atendimento psicológico, social, orientações e encaminhamentos jurídicos necessários à superação da situação de violência, contribuindo para o fortalecimento da mulher e o resgate de sua cidadania.

Além dos atendimentos individuais oferecidos às mulheres, no CDCM é oportunizado a participação das mulheres em oficinas grupais em encontros semanais e regulares, facilitadas por especialistas em diversos temas, cujo trabalho com a Musicoterapia foi oferecido como uma dessas propostas.

A seguir um relato da autora como musicoterapeuta trabalhadora do Centro de Defesa e Convivência da Mulher (CDCM) Helena Vitória.

$O$ trabalho de musicoterapia com as mulheres foi disponibilizado às usuárias do serviço entre o início de 2018 e novembro de 2020 de forma regular e contínua através de atendimentos semanais. O objetivo principal da atividade foi oferecer às participantes a oportunidade da vivência coletiva de experiências musicais, que estimulem 0 autocuidado e o fortalecimento individual e coletivo, para prevenção e enfrentamento à violência.

As propostas musicoterapêuticas estavam alinhadas aos objetivos do serviço, ou seja, estimulavam o exercício da cidadania e da participação social a fim de contribuir para o acesso aos direitos das mulheres. Além disso, foram adotadas perspectivas feministas para guiar a prática terapêutica a fim de promover uma terapia não sexista, livre dos estereótipos, e comprometida com as pautas das desigualdades de gênero, raça e classe (NARVAZ e KOLLER, 2006).

As atividades se desenvolveram a partir de experiências coletivas de improvisação musical, jogos, brincadeiras, dinâmicas musicais, percussão corporal, canto, composição e escuta, sempre com espaço para debate e reflexão sobre os insights, sensações e sentimentos despertados. Uma experiência musical de destaque nos encontros foi a composição coletiva, com 
a criação de canções que retratam as histórias de vida das mulheres e suas identidades culturais e sociais.

As beneficiárias diretas são as mulheres usuárias do serviço. No grupo de musicoterapia as participantes são em sua maioria mulheres idosas. Contudo, podemos identificar pessoas que se beneficiavam indiretamente, como as demais usuárias participantes das outras oficinas, as crianças e adolescentes que estavam acompanhando suas cuidadoras no local, que assistiam as apresentações, viam as composições expostas no mural do serviço e observavam as transformações na história e vida das companheiras que frequentam as atividades.

\section{A Pandemia de COVID-19 e os impactos no atendimento}

Segundo Vieira, Garcia e Maciel (2020) Organizações voltadas ao enfrentamento da violência doméstica observaram o aumento desse tipo de violência durante o período da pandemia por causa da coexistência forçada, do estresse econômico e de temores sobre o coronavírus, embora as evidências a respeito dos impactos do isolamento sobre a violência doméstica e familiar ainda sejam incipientes. Nesse sentido, houve a necessidade de uma rápida reestruturação de todas as atividades desenvolvidas nos serviços, bem como das formas de atendimento, buscando suporte às usuárias. A seguir, um relato sobre essa reestruturação e os impactos sofridos nas atividades de musicoterapia ministradas pela autora no CDCM Helena Vitória.

Os atendimentos presenciais do CDCM foram interrompidos no final de março de 2020, e o meio principal para manutenção de contato com as mulheres, para realização do atendimento jurídico, psicológico e de assistência social se deu primordialmente através de contato telefônico.

Revista Brasileira de Musicoterapia - Ano XXIIn 28 ANO 2020 
Levando em consideração a grande dificuldade de acesso à internet e manejo das plataformas e aparelhos por parte das usuárias, a proposta da oficina de musicoterapia passou a ser oferecida de forma assíncrona utilizando o aplicativo de mensagens "WhatsApp". Há de se registrar também, que as dificuldades envolvendo acesso às Tecnologias de Informação e Comunicação (TICs) também se apresentaram à musicoterapeuta responsável pelo grupo, sendo um elemento importante para decisão do formato utilizado (assíncrono).

Deste modo, o envio de propostas se deu em formato de texto ou vídeo que podia ser enviado de duas formas: vídeo compactado para consumir menos dados móveis dos celulares das mulheres, possibilitando o download por pacotes de internet mais populares, ou link para plataforma "Youtube" para quem pudesse acessar internet fora do aplicativo de mensagens.

As experiências musicais (Bruscia, 2016) propostas de forma assíncrona foram principalmente: experiência re-criativas - re-criação instrumental e vocal, produções musicais, jogos musicais e condução; experiências de composição paródias de canções, escrever canções e colagens musicais; experiências receptivas - escuta perceptiva, escuta para a ação, escuta meditativa, reminiscência musical, discussão de canções, escuta projetiva, associação livre, e atividades de apreciação musical.

Grande parte do grupo de mulheres idosas não possui smartphones, e possuem dificuldades no manejo de TICs, e, portanto, não conseguiram se adaptar para participar das propostas, o que foi uma grande perda visto que elas eram participantes assíduas nos encontros anteriores à pandemia.

No início da transição para esse formato, muitas mulheres tiveram dificuldade de interagir no grupo e, portanto, de dar retornos sobre o andamento da realização das propostas. Aos poucos, musicoterapeuta e usuárias do serviço foram encontrando formas de manter a interação e a realização de atividades criativas utilizando a menor quantidade de recursos materiais possíveis. Mesmo assim, em comparação com a participação nas

Revista Brasileira de Musicoterapia - Ano XXIIn 28 ANO 2020

PAZ, Kezia."Como é que faz pra sair da ilha?" Pontes e atravessamentos entre a pandemia, o SUAS e a musicoterapia

(p. $53-70)$ 
atividades presenciais, a interação com as propostas assíncronas se manteve baixa.

Foi pactuado, que todo o conteúdo disponibilizado no grupo online deveria ser resguardado pelas mulheres, tornando todas responsáveis por manter esse espaço seguro, e aberto para troca. O espaço do grupo tornou-se um canal não só de contato, mas também de reminiscências dos momentos anteriores à pandemia, de resgate das construções e composições coletivas, e também para compartilhar o novo dia-a-dia imposto pela pandemia. $O$ trabalho com a memória sonoro-musical se evidenciou, pela própria atitude das mulheres em referenciar momentos vividos na oficina presencial, bem como para resgatar músicas e sonoridades que compunham suas histórias em diversos aspectos.

Eram frequentes os relatos sobre saudade e a vontade de retomada dos encontros presenciais para "cantar" e "fazer música" coletivamente. Porém, o receio do contágio, e a responsabilidade com familiares mais vulneráveis com relação à saúde se sobrepuseram. Quase que a totalidade das mulheres afirmaram se sentir confortáveis com o retorno somente após a garantia da vacina contra o coronavírus para toda a população.

A musicoterapia nesse contexto deveria ser uma via importante para composição da rede de apoio a essas mulheres no contexto da pandemia. Porém pela falta de acessibilidade $o$ impacto da conjuntura política nos seus modos de viver ainda foi bastante percebido. A musicoterapia sugeriu caminhos de enfrentamento a esse momento complexo, em suas casas, utilizando recursos que estimulavam a criatividade, o contato com o próprio corpo, a escuta atenta de si mesma e do seu entorno, e principalmente, a valorização de uma memória sonoro musical afetiva que envolvia o encontro e o espaço coletivo que a musicoterapia provocava. Mas apesar de toda essa potência, há que se destacar que foram consideráveis os impactos da pandemia no atendimento, principalmente no que se refere a baixa na 
participação e alcance das atividades, e na construção de processos coletivos, principal característica dos encontros sonoro-musicais anteriores à pandemia.

\section{Algumas perguntas, para não concluir}

A Pandemia de COVID19 trouxe para a categoria de musicoterapeutas a possibilidade de aprofundarmos a reflexão sobre questões acerca da acessibilidade da Musicoterapia a populações mais vulnerabilizadas, e a visão da classe sobre a importância da prática em caráter social e comunitário.

$\mathrm{Na}$ experiência aqui relatada, podemos observar impactos significativos na manutenção dos atendimentos musicoterapêuticos realizados, visto que a condição socioeconômica das mulheres é um elemento que reflete na falta de acesso às TICs. Nessa perspectiva observamos uma atuação em Musicoterapia Social e Comunitária que corrobora com a afirmação de Arndt e Maheirie (2019), quando dizem que a musicoterapia social e comunitária é "um tipo de prática que se insere para atuar com o cotidiano e no cotidiano da população com quem se trabalha" (ARNDT; MAHEIRIE 2019 pg. 67).

Outro ponto a ser destacado é o fato de que grande parte dos trabalhos em políticas públicas e em caráter sócio comunitário, acontecem de forma grupal, algo que sofreu grande impacto com as normativas de distanciamento social impostas pela pandemia. Considerando ainda que a população que acessa tais práticas são mais vulnerabilizadas e pertencem a classes sociais mais baixas.

Além disso, como foi pontuado, a dificuldade com as Tecnologias da Informação e Comunicação (TICs) também se apresentaram à musicoterapeuta frente a esse grupo, destacando que trata-se de uma trabalhadora de uma política pública sucateada, e que isso implica diretamente nos recursos oferecidos para a realização de um trabalho de qualidade. Nesse sentido, devemos refletir sobre a responsabilização do poder público, e não

Revista Brasileira de Musicoterapia - Ano XXIIn² 28 ANO 2020

PAZ, Kezia. "Como é que faz pra sair da ilha?" Pontes e atravessamentos entre a pandemia, o SUAS e a musicoterapia 
apenas sobre a responsabilização individual de profissionais que atuam nesse campo.

Cabe ressaltar que a trabalhadora foi desligada do serviço em questão durante o processo de revisão desse artigo, corroborando com a análise de conjuntura no início do texto que aponta as fragilidades das relações de trabalho terceirizadas. Devido a uma mudança de gestão em meio ao período eleitoral, o CDCM Helena Vitória passou a ser "reformulado", segundo palavras da nova gerência, que assim justificou os motivos para desligar diversas trabalhadoras sem que as usuárias dos serviços fossem consultadas.

Vemos portanto a necessidade de discutirmos conjuntamente caminhos para promover acesso a nossa prática, bem como refletir sobre o que temos difundido até aqui de aporte teórico, conceitual e prático no que se refere a uma atuação sob uma perspectiva político-social, que considere não só o contexto desigual e diverso da qual muitos públicos atendidos por nós pertence, mas também sobre a desigualdade e diversidade imposta aos musicoterapeutas trabalhadores de políticas públicas, ou de campos mais fragilizados, como terceiro setor, ambos muito impactados pela conjuntura pandêmica.

\section{Considerações finais, ainda para não concluir}

Todas as questões trazidas no tópico anterior são extremamente complexas para serem respondidas apenas em um artigo reflexivo. É necessário ampliar pesquisas na área, fortalecer ações práticas e incorporar a importância de ampliar esse debate.

A Pandemia de COVID-19 trouxe para a categoria de musicoterapeutas a oportunidade de aprofundarmos a reflexão acerca da acessibilidade da Musicoterapia para populações mais vulnerabilizadas. É necessário o 
fortalecimento de espaços de participação e controle social pelos musicoterapeutas, e o reconhecimento da categoria como classe trabalhadora, que assim como outras categorias, sofre impactos do contexto político em vigência.

Espera-se portanto com esse artigo, dar visibilidade a essa temática e suas problemáticas no campo da musicoterapia, e ao mesmo tempo sensibilizar a categoria para o entendimento de que com organização e mobilização coletiva da classe de musicoterapeutas, é possível criar novas pontes entre a musicoterapia e a população que dela precisa.

\section{REFERÊNCIAS:}

ANDRADE, Maeve; CUNHA, Rosemyriam. A dimensão da saúde no contexto da prática da Musicoterapia Social. Revista Brasileira de Musicoterapia, XVII, v. 18, p. 64-84, 2015.

ARNDT, Andressa Dias; MAHEIRIE, Kátia. Musicoterapia: dos fazeres biomédicos aos saberes sociocomunitários. Revista Polis e Psique, v. 9, n. 1, p. 54-71, 2019.

ARNDT, Andressa Dias. Musicoterapia Social e Comunitária: ações coletivas em pauta. Revista Pesquisas e Práticas Psicossociais, v. 15, n. 2, p. 1-15, 2020.

ARNDT, Andressa Dias. "Mas, nós vamos compor?": Roda de música como experiência coletiva em um CRAS da região metropolitana de Curitiba. Dissertação(Mestrado) Universidade Federal de Santa Catarina, Centro de Filosofia e Ciências Humanas, Programa de Pós-Graduação em Psicologia, Florianópolis, p.196. 2015.

BRUSCIA, Kenneth. Definindo Musicoterapia. $3^{\circ}$ ed. Dallas Barcelona Publisher, 2016.

CHAGAS, Marly; BRASIL Cristiana; CABRAL Bárbara Penteado. Precisamos falar sobre política. Revista Brasileira de Musicoterapia - Ano XX n²4, p.7290, 2018.

Revista Brasileira de Musicoterapia - Ano XXIIn² 28 ANO 2020 
CNDAS - Caderno da Conferência Nacional Democrática da Assistência Social, Conselho Nacional de Assistência Social (CNAS), 2019. Disponível em <https://drive.google.com/file/d/1NjSjc1l6GDiNia3Hn9ZZtaZo4n-Ngmal/view> Acesso em 20/10/2020.

CUNHA, Rosemyriam. Musicoterapia Social e Comunitária: uma organização crítica de conceitos. Revista Brasileira de Musicoterapia, XVIII, v. 21, p. 93116, 2016.

DE OLIVEIRA, Patrícia Araújo; KAHHALE, Edna Maria Severino Peters. Uma história do Sistema Único de Assistência Social (SUAS), a participação do psicólogo e possibilidades de atuação. Revista Psicologia Política, v. 20, n. 47, p. 119-131, 2020.

DREHER, Sofia Cristina. A musicoterapia e sua inserção nas políticas públicas- análise de uma experiência. Revista Brasileira de Musicoterapia, n.11, p.11- 36, 2011.

GONDAR, Jô. A clínica como prática política. Lugar Comum: Estudos de Mídia, Cultura e Democracia, v. 19, p. 125-34, 2004.

IKEDA, Alberto Tsuyoshi. Música, política e ideologia: algumas considerações. ANAIS DO V SIMPÓSIO LATINO-AMERICANO DE MUSICOLOGIA, p. 1-14, 2001.

KROB, Daniéli Busanello; SILVA, Laura Franch Schmidt. Comigo não, violão!": Musicoterapia com mulheres em situação de violência doméstica. Revista Brasileira de Musicoterapia, XIV, v. 13, p. 27-38, 2012.

KROB, Daniéli Busanello. Desconstruindo Amélias: musicoterapia com mulheres em situação de violência doméstica sob a ótica da teologia feminista. Dissertação(Mestrado em Teologia) Faculdades EST - São Leopoldo, p.131, 2013.

LOTTA, Gabriela; MAGRI, Giordano; ALIBERTI, Cláudio; CORRÊA, Marcela Garcia; BECK, Amanda Lui; BARCELLOS, Taciana. A pandemia de COVID-19 e os profissionais de assistência social no Brasil: $1^{\text {a }}$ fase - Julho/2020 Nota técnica. Fundação Getúlio Vargas, Núcleo de Estudos da Burocracia, 2020. Disponível em: <https://neburocracia.files.wordpress.com/2020/06/rel03social-covid-19-depoimentos.pdf> Acesso em 19/10/2020.

LOTTA, Gabriela; MAGRI, Leonardo; ALIBERTI, Claudio; CORRÊA, Marcela Garcia; BECK Amanda Lui; BARCELLOS, Taciana. A pandemia de COVID-19

Revista Brasileira de Musicoterapia - Ano XXIIn² 28 ANO 2020

PAZ, Kezia."Como é que faz pra sair da ilha?" Pontes e atravessamentos entre a pandemia, o SUAS e a musicoterapia

(p. $53-70)$ 
e os profissionais de assistência social no Brasil: $2^{\text {a }}$ fase - Agosto/2020 Nota técnica. Fundação Getúlio Vargas, Núcleo de Estudos da Burocracia, 2020. Disponível em: <https://neburocracia.files.wordpress.com/2020/08/rel08social-covid-19-fase-2-v4.pdf> Acesso em: 19/10/2020.

NARVAZ, Martha Giudice; KOLLER, Sílvia Helena. Metodologias feministas e estudos de gênero: articulando pesquisa, clínica e política. Psicologia em estudo, v. 11, n. 3, p. 647-654, 2006.

OSELAME, Mariane N. Um estudo sobre as práticas da Musicoterapia em direção à promoção da saúde. Dissertação (mestrado) Universidade Federal do Rio de Janeiro, Instituto de Psicologia, Programa de Pós-Graduação em Psicossociologia de Comunidades e Ecologia Social - EICOS, p.105, 2013.

PELLIZZARI, Patricia.CrearSalud. Aportes de la Musicoterapia Preventiva Comunitaria. PatriciaPellizzari Editora, Buenos Aires, 2011.

PELLIZZARI, Patrícia. Musicoterapia comunitária, contextos e investigación. Revista Brasileira de Musicoterapia, ano XII, n. 10, p.12, 2010.

REIS, Marina; FREIRE, Marina. A musicoterapia sob um olhar político: Reflexões a partir de entrevistas. Revista InCantare, v. 11, n. 2, 2020.

RNSP - Rede Nossa São Paulo. Mapa da Desigualdade 2019. Disponível em: <https://www.nossasaopaulo.org.br/wp-content/uploads/2020/10/Mapa-daDesigualdade-2020-TABELAS-1.pdf> Acesso em: 07/11/2020.

SNAS - Secretaria Nacional de Assistência Social. Serviço de Informação ao Cidadão - Brasília, 2020. Disponível em: <https://www.gov.br/acessoainformacao/pt-br/falabr> Acesso em 28/07/2020.

STEFFEN, Luciana. Diferenças de gênero no cuidado de meninas e meninos com deficiência. In: ANAIS DO CONGRESSO INTERNACIONAL DA FACULDADES EST.p. 1469-1483, 2012.

STEFFEN, Luciana. Musicoterapia com práxis teológica: interseções entre gênero e deficiência no desenvolvimento da independência de crianças e adolescentes com deficiência em atendimento musicoterapêutico. Dissertação (Mestrado em Teologia) Faculdades EST, São Leopoldo, p. 174,2014

Revista Brasileira de Musicoterapia - Ano XXIIn² 28 ANO 2020

PAZ, Kezia."Como é que faz pra sair da ilha?" Pontes e atravessamentos entre a pandemia, o SUAS e a musicoterapia

(p. $53-70)$ 
SANTANA, Fabrícia Santos. A musicoterapia na política nacional de assistência social. Dissertação (Mestrado em Música) - Universidade Federal de Goiás, Goiânia, p.281,2016.

SANTOS, Hermes Soares. Era uma casa bem bagunçada... Uma canção de um grupo de mulheres residentes em um abrigo para vítimas de violência doméstica. Revista InCantare, v. 10, n. 1, p.127-146,2019.

SANTOS, Marcello Silva. Contemporaneidades e Produção de Conhecimento: A Invenção da Profissão de Musicoterapeuta. Tese (Doutorado em Psicossociologia e Ecologia Social) Universidade Federal do Rio de Janeiro, Instituto de Psicologia, Programa EICOS, p.171,2011.

VALENTIN, Fernanda. "Não é porque eu sou pobre que eu não posso sonhar": contribuições da musicoterapia em um grupo multifamiliar vulnerado pela pobreza. Tese (Doutorado em Psicologia Clínica e Cultura) Universidade de Brasília, Brasília, p.222, 2018.

VIEIRA, Pâmela Rocha; GARCIA, Leila Posenato; MACIEL, Ethel Leonor Noia. Isolamento social e o aumento da violência doméstica: o que isso nos revela? Revista Brasileira de Epidemiologia [online]. v. 23 [Acessado 7 de fevereiro 2021], e200033. Disponível em: <https://doi.org/10.1590/1980-549720200033>. 